\title{
Validation of Loop-Mediated Isothermal
} Amplification (LAMP) Field Tool for Rapid and Sensitive Diagnosis of Contagious Agalactia in Small Ruminants

\author{
Serena Tumino ${ }^{1,2, *(\mathbb{D}}$, Marco Tolone ${ }^{2,3}$, Alessio Parco $\left.{ }^{2}{ }^{(}\right)$, Roberto Puleio ${ }^{2}{ }^{(}$, \\ Giuseppe Arcoleo ${ }^{4}$, Claudia Manno ${ }^{5}$, Robin A.J. Nicholas ${ }^{6}$ and Guido Ruggero Loria ${ }^{2}$ \\ 1 Dipartiment of Agricultural, Food and Environmental Science, University of Catania, 95123 Catania, Italy \\ 2 Istituto Zooprofilattico Sperimentale della Sicilia “A. Mirri”, 90129 Palermo, Italy; \\ marco.tolone@unipa.it (M.T.); alessio.parco@gmail.com (A.P.); roberto.puleio@izssicilia.it (R.P.); \\ guidoruggero.loria@izssicilia.it (G.R.L.) \\ 3 Department of Agricultural, Food and Forestry Science, University of Palermo, 90128 Palermo, Italy \\ 4 Enbiotech SRL, 90129 Palermo, Italy; g.arcoleo@enbiotech.eu \\ 5 AVANTECH GROUP SRL, 84012 Angri, Italy; manno@avantech.it \\ 6 The Oaks, Nutshell Lane, Farnham, Surrey GU9 0HG, UK; robin.a.j.nicholas@gmail.com \\ * Correspondence: serena.tumino@unict.it; Tel.: +39-095-4783476
}

Received: 28 February 2020; Accepted: 16 March 2020; Published: 19 March 2020

Simple Summary: Contagious agalactia (CA) is an infectious disease of small ruminants endemic in the Mediterranean countries, causing significant socioeconomic impacts predominantly on small-scale farmers who still subsist on marginal lands. Mycoplasma agalactiae is historically considered the principal etiological agent of CA, especially in sheep. Clinical signs are characterised by mastitis, arthritis, keratoconjunctivitis and occasionally, abortion. Rapid, accurate and cost-effective field tests are urgently needed for effective control of $M$. agalactiae mastitis. Our study illustrated the validation of a Loop-Mediated Isothermal Amplification (LAMP) test for the detection of M. agalactiae in dairy sheep in order to confirm its application as a diagnostic tool in the field level.

\begin{abstract}
Contagious agalactia (CA), an infectious disease of small ruminants, caused by Mycoplasma agalactiae, is responsible for severe losses to dairy sheep production with substantial socioeconomic impacts on small-scale farmers. The diagnosis of CA is still problematic, time-consuming and requires well-equipped labs for confirmation of outbreaks. Therefore, rapid, accurate and cost-effective diagnostic tests are urgently needed. This work aims to validate a novel Loop-Mediated Isothermal Amplification (LAMP) test, based on the $p 40$ target gene, for the detection of M. agalactiae in dairy sheep in order to confirm its potential practical use as a rapid and cheap field test. The LAMP system proposed in this study consists of a portable device composed of real-time fluorometer with the automatic interpretation of results displayed in a tablet. A total of 110 milk samples (90 positives and 20 negatives) were analysed to optimise the analysis procedure and to investigate the efficacy and robustness of the LAMP method. All samples were analysed using LAMP and conventional real-time PCR to compare the diagnostic sensitivity of the methods. The sensitivity of the LAMP was 10-fold higher than that of real-time PCR, with a detection limit up to $10^{3} \mathrm{CFU} / \mathrm{ml}$. The LAMP assay was able to detect M. agalactiae in 81 of $90(90 \%, 95 \%$ CI $0.84-0.96)$ positive milk samples compared to $69(77 \%$, 95\%CI 0.59-0.95) positive samples detected by real-time PCR; no positive signal occurred for any of the negative milk samples in either test. Therefore, the LAMP assay was found to be more sensitive than real-time PCR, low-cost, easy to perform, fast and not affected by contamination, indicating its potential as an effective diagnostic tool in the field level for the diagnosis of CA.
\end{abstract}


Keywords: Mycoplasma agalactiae; field diagnostic test; $p 40$ gene; small ruminants; LAMP

\section{Introduction}

Contagious agalactia (CA) is an infectious disease of small ruminants endemic in the Mediterranean countries, and is commonly caused by Mycoplasma agalactiae. It is responsible for severe losses to dairy sheep production with substantial socioeconomic impacts on small-scale farmers, often subsisting on marginal land.

Clinical signs are characterized by mastitis, arthritis, keratoconjunctivitis and occasionally, abortion. The course of the disease starts as mild monolateral interstitial mastitis, with warm, swollen, painful parenchyma followed by sclerosis of the udder, alteration in the quality of milk with a drastic decline in dairy production [1-3].

Today in the Middle East and countries in the Mediterranean basin, the management of CA is one of the highest priorities for sheep and goat farming due to the severe losses in milk production, increased lamb mortality, cost of veterinary assistance and the difficulty of eradicating the infection once established in a herd. Considering the widespread distribution and economic impact, CA has been included as a notifiable disease listed by the OIE (World Organization for Animal Health) [1].

Early diagnosis is essential for the rapid and effective management of the disease in order to avoid the spread of the infection to the whole flock; therefore, rapid, precise, and low-cost methods for pathogen detection are urgently needed. Traditionally, according to OIE guidelines [1], the current diagnosis of CA is based on the isolation of causative mycoplasmas from affected animals, which are further identified by biochemical, serological or molecular tests such as PCR-based methods. The isolation of the mycoplasma in selective enrichment media represents a laborious and time-consuming process, as mycoplasmas grow very slowly. Furthermore, serological tests such as the enzyme immunoassay or complement fixation test may be ineffective in the first stage of the disease, which may result in false-negative cases because the antibodies are detectable only after 10-15 days from infection [4]. During the past decades, a number of polymerase chain reaction (PCR) and real-time quantitative PCR-based assays have been widely applied for rapid detection of M. agalactiae [5-7]. Nevertheless, disadvantages for PCR and real-time PCR such as the presence of inhibitors normally in milk and the requirement for trained staff and well-equipped laboratories limit their utilization as rapid tests and in-field practice. More recently, new molecular diagnostic tools have been developed to provide higher sensitivity, specificity and to reduce time and costs. Loop-Mediated Isothermal Amplification (LAMP) is an innovative and economic gene amplification tool based on its ability to amplify a target gene with high efficiency under isothermal conditions, unlike PCR, in the range of 60 to $65^{\circ} \mathrm{C}$ [8]. In comparison to the conventional PCR and real-time PCR, the LAMP technique is less sensitive to inhibitors present in biological samples. It does not require temperature cycling and can be performed using a simple heating device such as water bath; therefore, it can potentially be used for tests in the field [9]. LAMP is more specific and faster than PCR and real-time PCR because it employs four oligonucleotide primers, namely FIP (forward inner primer), BIP (backward inner primer), F3 (forward primer) and B3 (backward primer) to recognize six different regions of the target gene. Two extra primers, LF (loop forward) and LB (loop backward), are also incorporated in order to accelerate the amplification of reaction as well as enhance the specificity [10]. LAMP has been shown to be a sensitive and specific method for the detection of veterinary pathogens [11-14]. The detection of $M$. agalactiae by LAMP was first reported by Rekha et al. [15]. However, the method for the detection of M. agalactiae in milk, the most common sample received by laboratories, has not yet been validated on field samples.

The aim of this work is to validate a LAMP test, previously developed by Loria et al. [16] for the detection of M. agalactiae in sheep milk samples in order to confirm both its effectiveness and robustness as a diagnostic tool and its potential practical use as a rapid and cheap field test. 


\section{Materials and Methods}

\subsection{Samples Preparation}

The NCTC reference strain of M. agalactiae (NCTC 10123) and three wild strains of M. agalactiae (Sc 123/4; Pa 116/20; Pa 49/19), previously isolated and identified by the OIE Reference Laboratory for $\mathrm{CA}$ at the Istituto Zooprofilattico Sperimentale della Sicilia, were used in this study for the artificial contamination of milk. The wild strains of $M$. agalactiae have been isolated from milk of sheep and goats affected by interstitial mastitis. In detail, the etiological agent has been identified by standard laboratory approaches according to the World Organization for Animal Health-microbiological isolation [1] and denaturing gradient gel electrophoresis (DGGE) analysis [5] of DNA extracted from $1 \mathrm{~mL}$ of milk.

M. agalactiae strains were grown in modified Hayflick's medium and after incubation at $37^{\circ} \mathrm{C}$ in $5 \% \mathrm{CO}_{2}$ for $72 \mathrm{hrs}$, the broths were then stored at $-80^{\circ} \mathrm{C}$. M. agalactiae cultures at exponential growth were serially diluted and colony-forming units (CFU) were determined using standard procedures [17].

To assess the limit of detection (LOD) of the assay, pasteurized milk, previously checked to be DNA mycoplasma-free by DGGE analysis, was contaminated with $M$. agalactiae and serial dilutions were made in the range of $10^{7}$ to $10 \mathrm{CFU} / \mathrm{ml}$, according to Oravcovà et al. [6]. Overall, 60 previously pasteurized milk samples were spiked with a serial dilution of different wild strains of M. agalactiae to compare sensitivity between real-time PCR and LAMP. In addition, 30 different positive milk samples collected from Sicilian outbreaks and 20 negative samples were included in the test. The use of mycoplasma isolates from sheep and goats milk samples provided the highest level of clonal diversity for test specificity validation and the study results are valid for the source population and target population. Therefore, a total of 110 samples of milk (90 positives and 20 negatives) were used to investigate the efficacy of the new method. The genomic DNA used for the real-time PCR was extracted from $1 \mathrm{~mL}$ of positive and negative milk samples, using the InstaGene Matrix (Bio-Rad laboratories, Hercules, CA, USA) according to the manufacturer's instructions and our standard laboratory approach. For the Lamp assay, the DNA extraction was performed from $100 \mu \mathrm{l}$ of the milk sample, using a single step and an incubation at room temperature, using the reagents supplied for the kit. The conduct and reporting of each test were done blind to the other test results.

\subsection{TaqMan Real-Time-PCR}

We have compared the LAMP assay to a well-established real-time-PCR method. A TaqMan real-time PCR assay was run on a Bio-rad CFX96 real-time PCR detection system and it was performed to amplify the $p 40$ gene, using MAP40127F and MAP40235R primers together with a 6-carboxyfluorescein [FAM]-labelled MAP40160P probe, according to Oravcovà et al. [6].

An exogenous internal positive control (IPC) was incorporated into the PCR reaction mixture in order to assess the absence of the PCR inhibitors, according to the manufacturer's instructions (TaqMan®Exogenous Internal Positive Control Reagents-VICTMProbe-Applied Biosystem, Foster city, CA, USA).

\subsection{Lamp Assay}

The LAMP assay was carried out using the ICGENE device (Enbiotech Group s.r.l., Palermo, Italy). It is composed of a portable instrument and a kit developed for specific detection of M. agalactiae. The system is composed of a real-time fluorometer with the automatic interpretation of results by the direct visualization of the sigmoid curve in a tablet, using a specific application (Enbiotech Group s.r.l., Palermo, Italy).

Six primers targeting the p40 gene [15] were used (Table 1). Three $\mu \mathrm{L}$ of the extracted DNA samples was used to obtain the specific amplification of the target in a final volume of $55 \mu \mathrm{L}$, including $22 \mu \mathrm{L}$ of LAMP mix (Enbiotech, Palermo, Italy) containing freeze-dried primer and a master mix with reagents useful to carry out the test and $30 \mu \mathrm{L}$ of mineral oil. All reagent compositions are protected 
by trade secret. The optimal conditions for amplification were obtained at a temperature of $64{ }^{\circ} \mathrm{C}$ for $60 \mathrm{~min}$. Positive and negative DNA control included in the kit were also used. The positivity was assessed graphically by the direct visualization of the sigmoid curve on the device display.

Table 1. Primer sequences for Loop-Mediated Isothermal Amplification (LAMP) for detection of Mycoplasma agalactiae.

\begin{tabular}{lll}
\hline Primers & Length $\mathbf{( b p )}$ & \multicolumn{1}{c}{ Primer Sequence $\mathbf{( 5}^{\prime} \mathbf{- 3}^{\prime} \mathbf{)}$} \\
\hline F3 & 21 & GGTTTATTAACTGCGTCATCA \\
B3 & 19 & CAACAGTTGCATTCGTCTT \\
FIP & 46 & ACCTTATCACCATTATCTTGTGGATCAGTGCCTTTATTAGCTCGTA \\
BIP & 46 & AGCATTAGGTGAAGTTGTCAAAAATATTGAGCTTGCTTCAGGAATT \\
LF & 24 & GTGAATTTTCGTTCTTATCATCAC \\
LB & 26 & ACAAATCTAGGTGAAATAGTATTACC \\
\hline
\end{tabular}

\subsection{Statistical Analysis}

Statistical analyses were performed using the caret package in R [18]. Sensitivity (Se) was calculated as the proportion of samples identified as positive by the assay. Specificity ( $\mathrm{Sp}$ ) was calculated as the proportion of negative test results obtained among healthy controls. We also carried out a comparison of accuracy in terms of prevalence (P), positive predictive value (PPV) and negative predictive value (NPV) for real-time-PCR and LAMP methods. The study was performed in compliance with the Standards for Reporting of Diagnostic accuracy (STARD) statement [19].

\section{Results and Discussion}

For the evaluation of performance characteristics of LAMP assay, results were compared to those of the real-time PCR. As expected, the results showed that no positive signal occurred for any of the negative milk samples for both tests, confirming the specificity of the primer set for M. agalactiae reported in the literature $[15,16]$.

The LAMP assay was able to detect M. agalactiae in 81 of 90 positive milk samples vs. 69 positive samples detected by real-time PCR; therefore, LAMP technology was found to be more sensitive than real-time PCR with a sensitivity of $90 \%$ (95\% CI 0.84-0.96) and 77\% (95\% CI 0.59-0.95), respectively (Table 2). Although the sample size for test validation was not calculated a priori, considering 110 samples it was possible to obtain a test power of $90 \%$ (sensitivity).

Table 2. Comparison of real-time PCR and LAMP results.

\begin{tabular}{llllllllll}
\hline Test & TP & FP & FN & TN & P (\%) & Se (95\% CI) & Sp (95\% CI) & PPV & NPV (95\% CI) \\
\hline Real-time PCR & 69 & 0 & 21 & 20 & 0.82 & $0.77(0.59-0.95)$ & 1 & 1 & $0.49(0.44-0.54)$ \\
LAMP & 81 & 0 & 9 & 20 & 0.82 & $0.90(0.84-0.96)$ & 1 & 1 & $0.69(0.65-0.73)$ \\
\hline
\end{tabular}

TP: true positive; FP: false positive; FN: false negative; TN: true negative; P: Prevalence; Se: sensitivity; Sp: specificity; PPV: positive predictive value; NPV: negative predictive value.

The sensitivity of LAMP assays and real-time PCR was determined in terms of CFU by making 10-fold serial dilutions of milk contaminated with $M$. agalactiae. Real-time PCR was able to detect up to the level of $10^{4} \mathrm{CFU} / \mathrm{ml}$, while LAMP could detect up to $10^{3} \mathrm{CFU} / \mathrm{ml}$, indicating that LAMP was 10-fold more sensitive than real-time PCR. The processing time of the LAMP assay was within 45 min from the beginning of the amplification, rather more than the $55 \mathrm{~min}$ required for the real-time PCR (Figure 1). The NPV of the LAMP test was higher than the real-time PCR method (0.69\% vs. 0.49\%). 


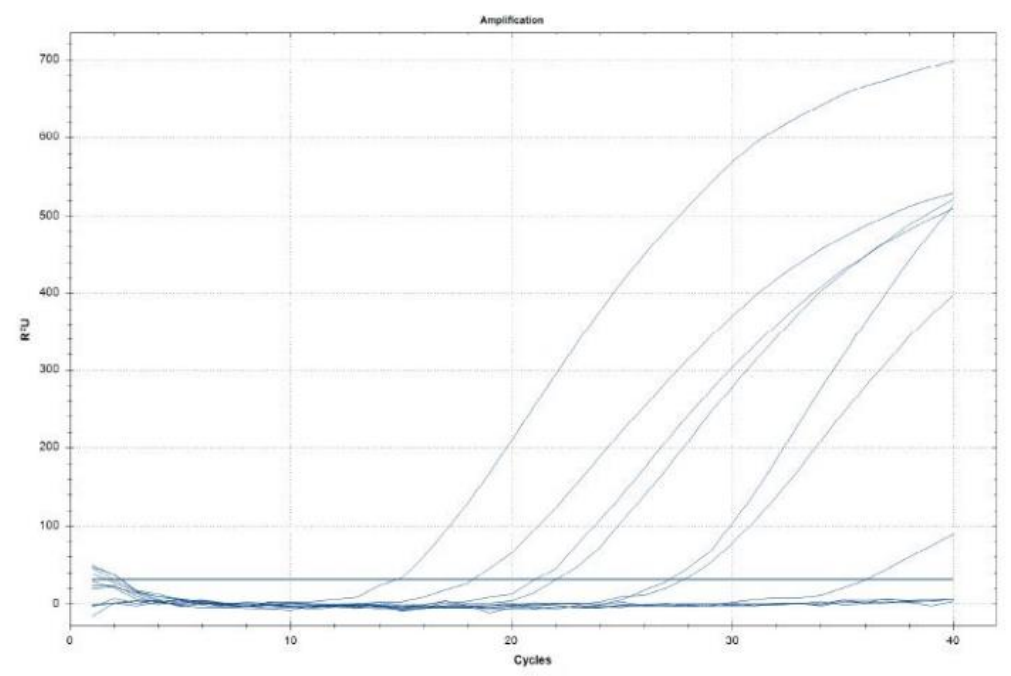

(a)
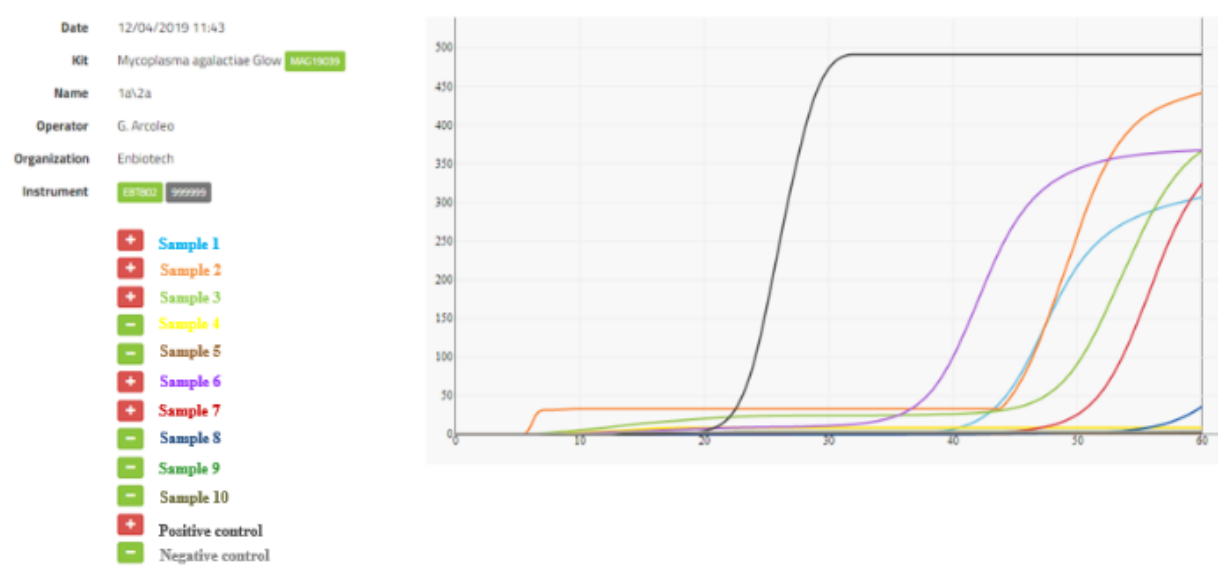

(b)

Figure 1. (a) Amplification curves obtained from real-time PCR and (b) LAMP assay.

Current diagnostic methods, using sheep and goats milk samples, include a variety of $M$. agalactiae-specific PCR-based assays [20]. In literature, these methods all extensively reported to have a high sensitivity and accuracy with a detection limit between 10 to $350 \mathrm{CFU} / \mathrm{ml}[6,7,21,22]$; a quite high level in comparison to our detection limits for both the methods (real-time PCR and LAMP). Furthermore, our LAMP LOD was not as good as those reported by other LAMP assays for the detection of other veterinary mycoplasma spp. [14,15,23,24]. However, it is known that performances of molecular diagnostic methods highly depend on the DNA extraction methods used and their efficiency to remove the natural inhibitors, which are present in the milk samples $[25,26]$.

Furthermore, the PCR-based assays require specific and expensive reagents, instruments and special precautions; thus, they are not suitable for application use in field, at great distances from diagnostic laboratories. On the other hand, The LAMP system with the mini portable instrument is inexpensive, requires little equipment and technical support, and is not space-consuming. In terms of turnaround time speed, the total time to detection, including the DNA extraction step, was only $1 \mathrm{hr}$ and $20 \mathrm{~min}$ using the ICGENE device, in comparison with $2 \mathrm{hrs}$ of real-time PCR procedure.

Moreover, the real-time PCR price per test (in euro, excluding Value-Added Tax) was estimated to be $24 €$ compared to $15 €$ (excluding Value-Added Tax) of the LAMP test price. 
Recently, a variety of isothermal amplification methods have been developed in the molecular diagnosis of a range of diseases and play a significant role in monitoring and controlling the spread of local epidemics in several countries [27]. Each of these existing techniques has advantages and disadvantages. However, it is known that the indirect detection methods like turbidity or also the colour change resulting from the use of hydroxynaphthol blue $[28,29]$ could be challenging to see by the naked eye. Other methods require opening the tube after amplification, such us running product on a gel and the addition of fluorescent dye (SYBR Green), causing carry-over contamination and detection of false-positive results [30-32]. In our experience, the best solution to avoid the risk for amplicon contamination is to use fluorescent dyes, detectable by amplification curves in real-time.

In our study, the ICGENE device has the advantage of being a portable device detecting the fluorescence emitted from the sample in real-time with the automatic interpretation of final results, observing the amplification curves on the tablet screen. Therefore, it is suitable for use directly in the field, and it does not require any process after thermal incubation, reducing the risk of environmental cross-contamination.

\section{Conclusions}

The results obtained confirmed that the LAMP assay is faster and has more sensitivity ( $90 \% \mathrm{vs.}$ $77 \%$ ) than the real-time PCR method. In conclusion, the LAMP portable device could be a potential field test, because it doesn't need the use of expensive laboratory equipment, does not require qualified staff and it is not affected by contamination.

Undoubtedly, speed, easiness and cost-effectiveness of the LAMP assay make it a promising and effective diagnostic tool in the field level for controlling Mycoplasma agalactiae infection.

Author Contributions: Conceptualization, G.R.L.; methodology, G.A. and C.M.; performance of the analyses, A.P., G.A. and C.M.; analysis of the data, A.P., S.T. and M.T.; formal analysis, M.T.; writing — original draft preparation, S.T.; revision and approval of the final draft, G.R.L., R.A.J.N. and R.P.; supervision, G.R.L. and R.P. All authors have read and agreed to the published version of the manuscript.

Funding: This research received no external funding.

Acknowledgments: Authors would like to thank all staff of the OIE Reference Laboratory for Contagious Agalactia belonging to the Istituto Zooprofilattico Sperimentale of Sicily, for their help in the sampling collection and processing process.

Conflicts of Interest: The authors declare no conflict of interest. The funders had no role in the design of the study; in the collection, analyses, or interpretation of data; in the writing of the manuscript, or in the decision to publish the results.

\section{References}

1. World Organization for Animal Health (OIE). Chapter 3.7.3 Contagious agalactia. In Manual of Diagnostic Tests and Vaccines for Terrestrial Animals (Terrestrial Manual), 8th ed.; OIE: Paris, France, 2018; Volume 1, pp. 1430-1440.

2. Nicholas, R.A.J.; Ayling, R.D.; Loria, G.R. Ovine mycoplasmal infections. Small Rumin. Res. 2008, 76, 92-98. [CrossRef]

3. Tolone, M.; Sutera, A.M.; Borrello, S.; Tumino, S.; Scatassa, M.L.; Portolano, B.; Puleio, R.; Nicholas, R.A.J.; Loria, G.R. Effect of Mycoplasma agalactiae mastitis on milk production and composition in Valle dell Belice dairy sheep. Ital. J. Anim. Sci. 2019, 18, 1067-1072. [CrossRef]

4. Buonavoglia, D.; Fasanella, A.; Greco, G.; Pratelli, A. A study on an experimental infection of sheep with Mycoplasma agalactiae. New Microbiol. 1999, 22, 27-30.

5. McAuliffe, L.; Ellis, R.; Lawes, J.; Ayling, R.D.; Nicholas, R.A.J. 16S rDNA and DGGE: A single generic test for detecting and differentiating Mycoplasma species. J. Med. Microbiol. 2005, 54, 1-9. [CrossRef]

6. Oravcova, K.; Lopez-Enriquez, L.; Rodriguez-Lazaro, D.; Hernandez, M. Mycoplasma agalactiae p40 gene, a novel marker for diagnosis of contagious agalactia in sheep by real-time PCR: Assessment of analytical performance and in-house validation using naturally contaminated milk samples. J. Clin. Microbiol. 2009, 47, 445-450. [CrossRef] [PubMed] 
7. Becker, C.A.; Ramos, F.; Sellal, E.; Moine, S.; Poumarat, F.; Tardy, F. Development of a multiplex real-time PCR for contagious agalactia diagnosis in small ruminants. J. Microbiol. Meth. 2012, 90, 73-79. [CrossRef] [PubMed]

8. Notomi, T.; Okayama, H.; Masubuchi, H.; Yonekawa, T.; Watanabe, K.; Amino, N.; Hase, T. Loop-mediated isothermal amplification of DNA. Nucleic Acids Res. 2000, 28, e63. [CrossRef] [PubMed]

9. Mori, Y.; Notomi, T. Loop-mediated isothermal amplification (LAMP): A rapid, accurate, and cost-effective diagnostic method for infectious diseases. J. Infect. Chemother. 2009, 15, 62-69. [CrossRef] [PubMed]

10. Nagamine, K.; Hase, T.; Notomi, T. Accelerated reaction by loopmediated isothermal amplification using loop primers. Mol. Cell. Probes 2002, 16, 223-229. [CrossRef]

11. Hill, J.; Beriwal, S.; Chandra, I.; Paul, V.K.; Kapil, A.; Singh, T.; Wadowsky, R.M.; Singh, V.; Goyal, A.; Jahnukainen, T.; et al. Loop-Mediated Isothermal Amplification Assay for Rapid Detection of Common Strains of Escherichia coli. J. Clin. Microbiol. 2008, 46, 2800-2804. [CrossRef]

12. Trangoni, M.D.; Gioffre, A.K.; Ceron Cucchi, M.E.; Caimi, K.C.; Ruybal, P.; Zumarraga, M.J.; Cravero, S.L. LAMP technology: Rapid identification of Brucella and Mycobacterium avium subsp. paratuberculosis. Braz. J. Microbiol. 2015, 46, 619-626. [CrossRef] [PubMed]

13. Sheet, O.H.; Grabowski, N.T.; Klein, G.; Abdulmawjood, A. Development and validation of a loop mediated isothermal amplification (LAMP) assay for the detection of Staphylococcus aureus in bovine mastitis milk samples. Mol. Cell. Probes 2016, 30, 320-325. [CrossRef]

14. Ashraf, A.; Imran, M.; Yaqub, T.; Tayyab, M.; Shehzad, W.; Mingala, C.N.; Chang, Y.F. Development and validation of a loop-mediated isothermal amplification assay for the detection of Mycoplasma bovis in mastitic milk. Folia Microbiol. 2018, 63, 373-380. [CrossRef] [PubMed]

15. Rekha, V.; Rana, R.; Thomas, P.; Viswas, K.N.; Singh, V.P.; Agarwal, R.K.; Arun, T.R.; Karthik, K.; Sophia, I. Development of loop-mediated isothermal amplification test for the diagnosis of contagious agalactia in goats. Trop. Anim. Health Prod. 2015, 47, 581-587. [CrossRef] [PubMed]

16. Loria, G.R.; Puleio, R.; Nicholas, R.A.J.; Manno, C.; Arcoleo, G.; Drago, C. A novel LAMP field test for the diagnosis of contagious agalactia caused by Mycoplasma agalactiae. Anim. Husb. Dairy Vet. Sci. 2018, 2. [CrossRef]

17. Rodwell, A.W.; Whitcomb, R.F. Methods for direct and indirect measurement of mycoplasma growth. In Methods in Mycoplasmology, Mycoplasma Characterization; Razin, S., Tully, J.G., Eds.; Academic Press: New York, NY, USA, 1983; Volume 1, pp. 185-196.

18. Kuhn, M. Building predictive models in R using the caret package. J. Stat. Softw. 2008, 28, 1-26. [CrossRef]

19. Bossuyt, P.M.; Reitsma, J.B.; Bruns, D.E.; Gatsonis, C.A.; Glasziou, P.P.; Irwig, L.; Lijmer, J.G.; Moher, D.; Rennie, D.; de Vet, H.C.W.; et al. STARD 2015: An updated list of essential items for reporting diagnostic accuracy studies. BMJ 2015, 351, h5527. [CrossRef]

20. Jaÿ, M.; Tardy, F. Contagious Agalactia in Sheep and Goats: Current Perspectives. Vet. Med. 2019, 10, $229-247$. [CrossRef]

21. Tola, S.; Angioi, A.; Rocchigiani, A.M.; Idini, G.; Manunta, D.; Galleri, G.; Leori, G. Detection of Mycoplasma agalactiae in sheep milk samples by polymerase chain reaction. Vet. Microbiol. 1997, 54, 17-22. [CrossRef]

22. Lorusso, A.; Decaro, N.; Greco, C.; Fasanella, A.; Buonavoglia, D. A real-time PCR assay for detection and quantification of Mycoplasma agalactiae. J. Appl. Microbiol. 2007, 103, 918-923. [CrossRef]

23. Kursa, O.; Woźniakowski, G.; Tomczyk, G.; Sawicka, A.; Minta, Z. Rapid detection of Mycoplasma synoviae by loop-mediated isothermal amplification. Arch. Microbiol. 2015, 197, 319-325. [CrossRef] [PubMed]

24. Zhang, J.; Cao, J.; Zhu, M.; Xu, M.; Shi, F. Loop-mediated isothermal amplification-lateral-flow dipstick (LAMPLFD) to detect Mycoplasma ovipneumoniae. World J. Microbiol. Biotechnol. 2019, 35, 31. [CrossRef] [PubMed]

25. Tatay-Dualde, J.; Sanchez, A.; Prats-van der Ham, M.; Gomez-Martin, A.; Paterna, A.; Corrales, J.C.; de la Fe, C.; Contreras, A.; Amores, J. Sensitivity of two methods to detect Mycoplasma agalactiae in goat milk. Ir. Vet. J. 2015, 68, 21. [CrossRef] [PubMed]

26. Tardy, F.; Treilles, M.; Gay, E.; Ambroset, C.; Tricot, A.; Maingourd, C.; Vialard, J.; Le Grand, D. Contagious agalactia monitoring in caprine herds through regular bulk tank milk sampling. J. Dairy Sci. 2019, 102, 5379-5388. [CrossRef] [PubMed]

27. Li, Y.; Fan, P.; Zhou, S.; Zhang, L. Loop-mediated isothermal amplification (LAMP): A novel rapid detection platform for pathogens. Microb. Pathog. 2017, 107, 54-61. [CrossRef] 
28. Soleimani, M.; Shams, S.; Majidzadeh, A.K. Developing a real-time quantitative loop-mediated isothermal amplification assay as a rapid and accurate method for detection of Brucellosis. J. Appl. Microbiol. 2013, 115, 828-834. [CrossRef]

29. Goto, M.; Honda, E.; Ogura, A.; Nomoto, A.; Hanaki, K.I. Colorimetric detection of loop mediated isothermal amplification reaction by hydroxy napthol blue. Biotechniques 2009, 46, 167-172. [CrossRef]

30. Iwamoto, T.; Sonobe, T.; Hayashi, K. Loop-mediated isothermal amplifcation for direct detection of Mycobacterium tuberculosis complex, M. avium, and M. intracellulare in sputum samples. J. Clin. Microbiol. 2003, 41, 2616-2622. [CrossRef]

31. Parida, M.; Sannarangaiah, S.; Dash, P.K.; Rao, P.V.L.; Morita, K. Loop mediated isothermal amplification (LAMP): A new generation of innovative gene amplification technique; perspectives in clinical diagnosis of infectious diseases. Rev. Med. Virol. 2008, 18, 407-421. [CrossRef]

32. Lau, Y.L.; Meganathan, P.; Sonaimuthu, P.; Thiruvengadam, G.; Nissapatorn, V.; Chen, Y. Specific, sensitive, and rapid diagnosis of active toxoplasmosis by a loop-mediated isothermal amplification method using blood samples from patients. J. Clin. Microbiol. 2010, 48, 3698-3702. [CrossRef]

(C) 2020 by the authors. Licensee MDPI, Basel, Switzerland. This article is an open access article distributed under the terms and conditions of the Creative Commons Attribution (CC BY) license (http://creativecommons.org/licenses/by/4.0/). 